SCIENTIFIC REPORT

\title{
The angiopoietin/Tie-2 system in proliferative sickle retinopathy: relation to vascular endothelial growth factor, its soluble receptor Flt- 1 and von Willebrand factor, and to the effects of laser treatment
}

\author{
J S Mohan, P L Lip, A D Blann, D Bareford, G Y H Lip
}

Br J Ophthalmol 2005;89:815-819. doi: 10.1136/bjo.2004.058164

\begin{abstract}
Aim: To determine plasma levels of angiopoietin- 1 and angiopoietin-2 (Ang-1, Ang-2), their soluble receptor Tie-2, vascular endothelial growth factor (VEGF), its soluble receptor Flt-1 (as indices of angiogenesis), and von Willebrand factor (vWf, marking endothelial damage/ dysfunction) in sickle cell disease (SCD) patients with proliferative sickle retinopathy (PSR), with non-proliferative retinopathy (NPR), or no retinopathy (NR) and in control subjects with normal haemoglobin (AA subjects). In addition, to determine changes with panretinal laser photocoagulation (PRP) therapy.

Methods: Research indices were measured (ELISA) in 24 SCD patients who had PSR, 16 with NPR, 16 with NR, and from 23 AA subjects. Eight patients received PRP therapy and plasma was obtained before laser treatment and at 6 months after the last PRP session.

Results: Ang-1, Ang-2, VEGF, and vWf (but not Tie-2 or sFlt-1) were raised in SCD patients compared to $A A$ subjects $(p<0.01)$ but there were no differences among the three SCD subgroups. Significant correlations were between Ang-1 and VEGF, Ang-1 and Tie-2, and VEGF and sFlt-1 in patients with SCD ( $r=0.67-0.88)$. Plasma Ang-2, VEGF, sFlt-1, and vWf levels did not change, but Ang- 1 fell and Tie-2 rose significantly following PRP therapy.

Conclusions: SCD patients have raised plasma angiopoietins (Ang-1, Ang-2), VEGF, and vWf compared to AA subjects. These indices did not differ according to severity of retinopathy and only limited changes occurred following PRP. The elevated growth factor levels in SCD may have obscured any association with retinopathy.
\end{abstract}

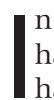
sickle cell disease (SCD), a group of inherited disorders of haemoglobin where pathology is caused by sickle ( $\mathrm{HbS}$ ) haemoglobin, the major pathophysiological basis of the morbidity and mortality is microvascular vaso-occlusion. Vaso-occlusion in the microcirculation of the peripheral retina in SCD results in ischaemia, a response to which is a sequence of pathological vascular events leading to proliferative sickle retinopathy (PSR), eventually causing visual loss in $10-12 \%$ of eyes. ${ }^{12}$ However, the determinants of PSR progression or autoinfarction are unknown. ${ }^{3}$

Vascular endothelial growth factor (VEGF), a potent, secreted growth factor that promotes angiogenesis, is a possible stimulus for retinal proliferation, as its expression is upregulated by hypoxia. ${ }^{4}$ High intraocular VEGF is found in patients with active intraocular neovascularisation, ${ }^{5}{ }^{6}$ supporting the view of a role in vasoproliferation/neovascularisation.
Changes in both plasma and intraocular VEGF levels have been related to laser treatment. ${ }^{5}$ VEGF interacts with endothelial cells via membrane spanning receptors Flt- 1 and KDR and the role of Flt-1 in embryonic vasculogenesis and adult angiogenesis and its association with several diseases has been clearly established. $^{8}$

Angiopoietin-1 and angiopoietin-2 (Ang-1, Ang-2), members of another family of vascular growth factors, interact with the endothelial cell specific tyrosine kinase receptor Tie-2. ${ }^{9}$ Ang- 1 acts via the Tie-2 receptor to remodel primitive vessels and help maintain and stabilise the mature vessels by promoting interaction between endothelial cells and surrounding support cells. ${ }^{10}{ }^{11}$ Ang-2, conversely, leads to destabilisation of vessels and dissociation of pericytes, and is upregulated by hypoxia and angiogenic cytokines, including $\operatorname{VEGF}^{12} 13$ and in pathological angiogenesis associated with tumours ${ }^{10}{ }^{11}$ and choroidal neovasculariation associated with age related macular degeneration. ${ }^{14}$ Thus, the precise balance of VEGF and the angiopoetin/Tie-2 system is essential for modulating growing vessels and maintaining the integrity of existing vessels, thereby determining whether vessels proliferate and become leaky.

Abnormally raised levels of VEGF have been reported in $\mathrm{SCD}^{15}$ but any role in associated eye disease is unclear. We therefore hypothesised abnormal Ang-1, Ang-2, sFlt-1, and sTie-2 in SCD, measuring VEGF as an effective positive control and vWf as an index of endothelial damage/ dysfunction. We further hypothesised a graded increase in these markers in SCD patients with no retinopathy (NR), others with non-proliferative retinopathy (NPR), and others with proliferative sickle retinopathy (PSR). To test these hypotheses, we undertook a cross sectional study. Finally, we hypothesised that these indices fall after treatment with panretinal laser photocoagulation (PRP), and conducted a longitudinal study, measuring our research indices before and 6 months after laser treatment.

\section{PATIENTS AND METHODS}

Patients with SCD who attended the Sickle Cell and Thalassemia (SCAT) Centre were recruited. Diagnosis (HbSS or HbSC) was proved using routine high performance liquid chromatography (HPLC). Patients were excluded if they had previously received laser treatment for proliferative retinopathy or had eye surgery, were receiving regular red cell exchange tranfusion, had blood tranfusion within the

Abbreviations: Ang, angiopoietin; HbS, sickle haemoglobin; HPLC, high performance liquid chromatography; NPR, non-proliferative retinopathy; NR, no retinopathy; $P R P$, panretinal laser photocoagulation; PSR, proliferative sickle retinopathy; SCD, sickle cell disease; VEGF, vascular endothelial growth factor; vWf, von Willebrand factor 
Table 1 Plasma levels of angiopoietin-1 (Ang-1) angiopoietin-2 (Ang-2), the soluble angiopoietin receptor Tie-2 (Tie-2), vascular endothelial growth factor (VEGF), its soluble receptor Flt-1, and von Willebrand factor (vWf) in patients with sickle cell disease (SCD) and subjects with normal haemoglobin (AA)

\begin{tabular}{|c|c|c|c|}
\hline & $\begin{array}{l}\text { AA subjects } \\
(n=23)(\text { IQR) }\end{array}$ & $\begin{array}{l}\text { SCD patients } \\
(\mathrm{n}=56) \text { (IQR) }\end{array}$ & p Value \\
\hline \multicolumn{4}{|l|}{ Raw data } \\
\hline Ang-1 (ng/ml) & $0.5(0.5-2.5)$ & $2.2(1.0-11.4)$ & 0.0004 \\
\hline Ang-2 (ng/ml) & $1.3(1.0-2.0)$ & $5.1(2.3-7.7)$ & $<0.001$ \\
\hline Tie-2 (ng/ml) & $10.8(10.0-12.0)$ & $7.7(5.5-28.3)$ & 0.105 \\
\hline VEGF $(\mathrm{pg} / \mathrm{ml})$ & $11(10-110)$ & $120(72-780)$ & $<0.001$ \\
\hline $\mathrm{sFlt-1}(\mathrm{ng} / \mathrm{ml})$ & $14.0(4-140)$ & $21.5(2.5-420)$ & 0.419 \\
\hline vWf (IU/dl) & $89(80-98)$ & $143(117.3-161)$ & $<0.001$ \\
\hline \multicolumn{4}{|l|}{ Ratios } \\
\hline Ang-2/VEGF & $100.0(28.0-136.0)$ & $23.5(9.2-56.2)$ & 0.009 \\
\hline Ang-2/Ang-1 & $2.2(0.6-2.8)$ & $1.4(0.7-3.1)$ & 0.825 \\
\hline Ang $1 /$ VEGF & $50.0(10-80)$ & $16.5(4.6-29.9)$ & 0.0058 \\
\hline (Ang-2/Ang-1) $\times 100 /$ VEGF & $12.0(1.7-26.0)$ & $1.4(0.07-4.6)$ & 0.0002 \\
\hline
\end{tabular}

The study cohort of 56 SCD (26 men, mean (SD) age $33.5(10)$ years) patients comprised 36 with $\mathrm{HbSC}$ disease and 20 with $\mathrm{HbSS}$ disease. Data in the SCD patients were compared with 24 healthy age, sex, and race matched controls (11 men, mean age 34.4 (SD 10) years).

In $\mathrm{HbSC}$ and HbSS disease, respective plasma levels of Ang-1 (median 1.7 (IQR 1-11.3) v 3.1 (2.0-11.4) ng/ml, $\mathrm{p}=0.0571)$, Tie-2 (7.0 (5.3-28.3) v $8.5(5.7-26.3) \mathrm{ng} / \mathrm{ml}, \mathrm{p}=0.436)$, VEGF $(115(60-413) \vee 122(103-6625)$ $\mathrm{pg} / \mathrm{ml}, \mathrm{p}=0.411)$, or sflt-1 $(13.8(1.3-295) \vee 48(11.3-490) \mathrm{ng} / \mathrm{ml}), \mathrm{p}=0.289)$, and $\mathrm{vWf} 133.5(113.5-155) \mathrm{v}$ 151.5 (133.3-168) IU/dl; $p=0.094$ ) did not differ between the groups, although Ang-2 was higher in the SS patients $(5.9(4.4-10) \vee 3.2(2.0-7.2) \mathrm{ng} / \mathrm{ml}) \mathrm{p}=0.025)$.

previous 3 months, had any malignancy, connective tissue disease or vascular disease, diabetes, hypertension, were pregnant, or were on long term medication (such as hydroxyurea). None of the patients had a painful crisis within 2 weeks of the time of ocular examinations and blood sampling. The healthy control group of subjects with normal haemoglobin genotype (AA subjects) were matched for age, sex, and ethnic origin with the PSR patients.

The diagnoses of PSR, NPR, or no retinopathy (NR) were made using slit lamp biomicroscopy and fluorescein angiography. ${ }^{5}$ The characteristic confirming feature of the diagnosis of peripheral retinal neovascularisation was intense hyperfluorescence caused by leakage of dye from new blood vessels. Patients with PSR who showed evidence of leakage on fluorescein angiogram ("leaky PSR") were offered laser treatment with sectoral panretinal photocoagulation (PRP).
A volume of $10 \mathrm{ml}$ of citrated venous blood was obtained for measurement of plasma Ang-1, Ang-2, Tie-2, VEGF, sFlt-1, and vWf. For patients with NR or with NPR, this was the only occasion on which a blood sample was taken. In patients with "leaky PSR" a blood sample was repeated at 5-7 (median 6 ) months after their last laser treatment. Blood samples were taken from the antecubital vein with minimal stasis into Vacuette tubes containing 3.2\% sodium citrate and centrifuged at $3000 \mathrm{rpm}$ at $4^{\circ} \mathrm{C}$ for 20 minutes. The platelet free plasma was immediately separated and frozen at $-70^{\circ} \mathrm{C}$. Research indices were measured by ELISA using commercially available reagents and recombinant standards (R\&D Systems, Abingdon, UK).

Data are presented as mean (SD) or median (interquartile range (IQR)) and compared by the unpaired $t$ test and by the Mann-Whitney $U$ test, or the one way ANOVA and

Table 2 Plasma levels of angiopoietin-1 (Ang-1) angiopoietin-2 (Ang-2), the soluble angiopoietin receptor Tie-2 (Tie-2), vascular endothelial growth factor (VEGF), its soluble receptor Flt-1, and von Willebrand factor ( $\mathrm{vWf}$ ) in patients with different manifestations of sickle eye disease

\begin{tabular}{lllll}
\hline & NR* & NPRT & PSR & p Value \\
\hline Raw data & & & & \\
Ang-1 (ng/ml) & $2.2(0.6-10.4)$ & $3.1(1.2-13.8)$ & $2.0(1.0-11.3)$ & 0.682 \\
Ang-2 (ng/ml) & $6.0(4.1-9.3)$ & $3.8(2.0-10.0)$ & $4.7(2.1-7.4)$ & 0.395 \\
Tie-2 (ng/ml & $6.3(5.0-36.0)$ & $9.0(6.1-31.5)$ & $7.4(5.8-22.0)$ & 0.714 \\
VEGF (pg/ml) & $108(61-728)$ & $116(72-2650)$ & $137(104-378)$ & 0.748 \\
sFlt-1 (ng/ml) & $35.0(3-421)$ & $16.5(0.3-500)$ & $18.8(6.1-278)$ & 0.941 \\
vWf (IU/dl) & $133(108-164)$ & $147(113-166)$ & $143(122-161)$ & 0.690 \\
Ratios & & & & \\
Ang-2/VEGF & $43.3(15.5-60.5)$ & $20.5(2.2-41.5)$ & $18.2(11.3-59.1)$ & 0.290 \\
Ang-2/Ang-1 & $2.4(0.8-4.3)$ & $1.1(0.6-2.3)$ & $1.6(0.7-3.1)$ & 0.260 \\
Ang-1/VEGF & $14.9(3.8-27.1)$ & $13.6(4.1-29.3)$ & $17.2(4.8-40.6)$ & 0.856 \\
(Ang-2/Ang-1)×100 /VEGF & $2.8(0.2-5.7)$ & $0.8(0.02-3.5)$ & $1.1(0.15-4.4)$ & 0.013 \\
\hline
\end{tabular}

The PSR group comprised 22 with $\mathrm{HbSC}$ and two with $\mathrm{Hb}$ SS (11 men, mean age 35 (SD 11$)$ ), NPR comprised nine with $\mathrm{HbSC}$ disease and seven with $\mathrm{HbSS}$ (seven men aged 34 (10) years), while the NR group was five with $\mathrm{HbSC}$ and 11 with $\mathrm{Hb}$ SS (eight men, aged 32 (10) years). There were more patients with HbSC in the PSR group $(p=0.008)$ but the differences in sex and age were not significant $(p=0.936, p=0.585$ respectively). NR, no retinopathy; NPR, non-proliferative retinopathy; PSR, proliferative retinopathy. ${ }^{*}$ No retinopathy bilaterally; tno retinopathy unilaterally or NPR unilaterally or NPR bilaterally; funilateral or bilateral PSR. Values are median (IQR) except for age, which is expressed as mean (SD). All p values by Mann-Whitney $U$ test except for age which is by the Student's unpaired $t$ test. 
Table 3 Correlations among plasma angiogenic growth factors, their receptors, and von Willebrand factor in 23 AA subjects and 56 SCD patients

\begin{tabular}{|c|c|c|c|c|c|c|}
\hline & vWf & VEGF & sFlt-1 & Ang-1 & Ang-2 & Tie-2 \\
\hline \multicolumn{7}{|c|}{23 AA subjects } \\
\hline VEGF & $-0.026,0.908$ & - & - & - & - & - \\
\hline sFlt-1 & $0.099,0.624$ & $0.627,0.001^{*}$ & - & - & - & - \\
\hline Ang-1 & $0.269,0.215$ & $0.505,0.014^{*}$ & $0.483,0.020^{*}$ & - & - & - \\
\hline Ang-2 & $0.209,0.338$ & $0.369,0.083$ & $0.244,0.263$ & $0.245,0.260$ & - & - \\
\hline Tie-2 & $-0.074,0.739$ & $0.546,0.007^{*}$ & $0.526,0.010^{*}$ & $0.501,0.015^{*}$ & - & - \\
\hline \multicolumn{7}{|c|}{56 SCD patients } \\
\hline VEGF & $0.120,0.380$ & - & - & - & - & - \\
\hline sFlt-1 & $0.114,0.401$ & $0.882,<0.001^{*}$ & - & - & - & - \\
\hline Ang-1 & $0.279,0.037^{*}$ & $0.677,<0.001^{*}$ & $0.610,<0.001^{*}$ & - & - & - \\
\hline Ang-2 & $0.165,0.225$ & $0.645,<0.001^{*}$ & $0.699,<0.001^{*}$ & $0.591,<0.001^{*}$ & - & - \\
\hline Tie-2 & $0.317,0.017$ & $0.743,<0.001$ * & $0.766,<0.001^{*}$ & $0.743,<0.001^{*}$ & $0.516,<0.001$ * & - \\
\hline
\end{tabular}

Data presented as Spearman correlation coefficient $(r)$ followed by $p$ values. * $p$ Values $<0.05$.

Ang-1: angiopoietin-1, Ang-2: angiopoietin-2, Tie-2: the angiopoietin receptor Tie-2, VEGF, vascular endothelial growth factor, sFlt-1, the VEGF receptor Flt-1; vWf, von Willebrand factor.

Kruskall-Wallis test as appropriate. Correlations were performed using Spearman's rank correlation test. Paired comparisons were tested using the paired Wilcoxon test.

\section{RESULTS}

Plasma levels of Ang-1, Tie-2, VEGF, sFlt-1, and vWf did not differ between the groups, although Ang-2 was higher in the SS patients $(p=0.025)$; therefore, data were pooled for further analysis. Plasma levels of Ang-1 and Ang-2 (but not Tie-2 or sFlt-1) were significantly raised in the SCD patients compared to levels in the AA subjects (table 1). As expected, ${ }^{15}{ }^{16}$ VEGF and vWf were higher in SCD. The ratios of Ang-2 to VEGF, Ang-1 to VEGF, and between all three growth factors (that is [Ang-1/Ang- $2 \times 100$ ]/VEGF) were lower in the SCD patients than in the controls but there was no statistical difference in the Ang-2/Ang-1 ratio. There were no differences in Ang-1, Ang-2, Tie-2, VEGF, sFlt-1, and vWf levels among the patients (table 2). The ratio [(Ang-1/ Ang-2) $\times 100] /$ VEGF was higher in NR than in the two other groups.

In the AA subjects, the most significant correlations were between Ang-1 and VEGF, Ang-1 and Tie-2, and VEGF and sFlt-1 (table 3). Stronger positive correlations were also apparent between the same molecules in the patients with SCD (table 3). Furthermore, in SCD, Ang-2 was highly correlated with Ang-1, Tie-2 with VEGF, and Ang-1 weakly with vWf. Within each of the SCD subgroups, Ang-1 was significantly correlated with Ang-2, with VEGF and with Tie-2; similarly, Ang-2 was significantly correlated with VEGF and Tie-2, (except in the NPR patients) and VEGF with sFlt-1 (table 4).

Plasma Ang-2 fell but Tie-2 rose significantly in eight patients (one male, mean age 34 (SD 9)) following PRP therapy (table 5), but Ang-1, VEGF, sFlt-1, and vWf levels did not change. Ocular examination showed only partial or incomplete resolution of neovascularisation at the time of the follow up blood sample in all the patients.

\section{DISCUSSION}

The current novel findings of elevated plasma Ang-2 in SCD, alongside raised VEGF, are consistent with the concept of increased angiogenic activity in SCD generally. The observations of elevated plasma VEGF ${ }^{15}$ (up to $\sim 10$-fold) and $\mathrm{vWf}^{16}$ confirm previous reports. The precise cause for the increased angiogenesis is unclear, but increased systemic tissue hypoxia consequent to generalised subclinical vaso-occlusion may contribute to the elevated plasma Ang-2 and VEGF levels. Marked endothelial damage/dysfunction is associated with $\mathrm{SCD}^{16}$ and endothelial proliferation as a means of effecting endothelial repair may be a mechanism for attempting to

Table 4 Correlations among angiogenic growth factors

\begin{tabular}{|c|c|c|c|c|c|c|}
\hline & vWf & VEGF & sFlt-1 & Ang-1 & Ang-2 & Tie-2 \\
\hline \multicolumn{7}{|c|}{16 SCD patients with no retinopathy } \\
\hline VEGF & $-0.331,0.210$ & - & - & - & - & - \\
\hline sFlt-1 & $-0.015,0.956$ & $0.743,0.001 *$ & - & - & - & - \\
\hline Ang-1 & $-0.044,0.872$ & $0.689,0.003^{*}$ & $0.492,0.053$ & - & - & - \\
\hline Ang-2 & $0.156,0.565$ & $0.745,0.001 *$ & $0.881,<0.001^{*}$ & $0.615,0.011^{*}$ & - & - \\
\hline Tie-2 & $0.156,0.564$ & $0.459,0.074$ & $0.742,0.001^{*}$ & $0.656,0.006^{*}$ & $0.712,0.002^{*}$ & - \\
\hline \multicolumn{7}{|c|}{16 SCD patients with non-proliferative retinopathy } \\
\hline VEGF & $0.094,0.730$ & - & - & - & - & - \\
\hline sFlt-1 & $0.076,0.779$ & $0.881,<0.001^{*}$ & - & - & - & - \\
\hline Ang-1 & $0.320,0.228$ & $0.756,<0.001^{*}$ & $0.773,<0.001^{*}$ & - & - & - \\
\hline Ang-2 & $0.037,0.891$ & $0.869,<0.001^{*}$ & $0.761,<0.001^{*}$ & $0.681,0.004^{*}$ & - & - \\
\hline Tie-2 & $0.413,0.112$ & $0.701,0.003^{*}$ & $0.688,0.003^{*}$ & $0.822,<0.001^{*}$ & $0.475,0.063$ & - \\
\hline \multicolumn{7}{|c|}{24 SCD patients with proliferative retinopathy } \\
\hline VEGF & $0.290,0.169$ & - & - & - & - & - \\
\hline sFlt-1 & $0.215,0.313$ & $0.935,<0.001^{*}$ & - & - & - & - \\
\hline Ang-1 & $0.477,0.018^{*}$ & $0.611,0.002^{*}$ & $0.470,0.020^{*}$ & - & - & - \\
\hline Ang-2 & $0.247,0.245$ & $0.549,0.005^{*}$ & $0.514,0.010^{*}$ & $0.589,0.002^{*}$ & - & - \\
\hline Tie-2 & $0.295,0.162$ & $0.871,0.000^{*}$ & $0.831,<0.001^{*}$ & $0.642,0.001^{*}$ & $0.477,0.019^{*}$ & - \\
\hline
\end{tabular}

Data presented as Spearman correlation coefficient $(r)$ followed by $p$ values. ${ }^{*} p$ Values $<0.05$.

Ang-1: angiopoietin-1, Ang-2: angiopoietin-2, Tie-2: the angiopoietin receptor Tie-2, VEGF: vascular endothelial growth factor, sFlt-1: the VEGF receptor Flt-1 and $v W f$ : von Willebrand factor. 
Table 5 The effect of laser treatment (PRP) on plasma levels of angiopoietin-1 (Ang-1) angiopoietin-2 (Ang-2), the soluble angiopoietin receptor Tie-2, VEGF, sFlt-1 and vWf in eight patients with sickle haemoglobin C disease with "leaky PSR"

\begin{tabular}{|c|c|c|c|}
\hline & \multicolumn{2}{|c|}{ HbSC patients with "leaky PSR" } & \multirow[b]{2}{*}{ p Value } \\
\hline & $\begin{array}{l}\text { Baseline } \\
\text { (pre-laser) }\end{array}$ & $\begin{array}{l}6 \text { months } \\
\text { post-laser }\end{array}$ & \\
\hline \multicolumn{4}{|l|}{ Raw data } \\
\hline Ang-1 (ng/ml) & $1.2(0.6-9.5)$ & $0.5(0.5-1.5)$ & 0.106 \\
\hline Ang-2 (ng/ml) & $3.6(1.5-7.2)$ & $1.1(1.1-2.0)$ & 0.022 \\
\hline Tie-2 (ng/ml & $6.0(5.5-7.8)$ & $10.0(7.6-10.6)$ & 0.022 \\
\hline VEGF (pg/ml) & $120(72-138)$ & $115(50-155)$ & 0.834 \\
\hline $\mathrm{sFlt}-1$ (ng/ml) & $15(5-138)$ & $0.1(0.01-3.6)$ & 0.402 \\
\hline$v W f(I U / d l)$ & $133(113-152)$ & $144(138-148)$ & 0.673 \\
\hline \multicolumn{4}{|l|}{ Ratios } \\
\hline Ang-2/VEGF & $16.1(12.2-101.1)$ & $20.0(9.3-23.5)$ & 0.076 \\
\hline Ang-2/Ang-1 & $3.1(1.0-4.3)$ & $2.3(0.77-2.7)$ & 0.035 \\
\hline Ang-1/VEGF & $16(4.8-28.2)$ & $10(8.8-13.2)$ & 0.151 \\
\hline (Ang-2/Ang-1 $\times 100) /$ VEGF & $2.6(0.5-8.0)$ & $1.7(0.6-4.6)$ & 0.554 \\
\hline
\end{tabular}

preserve endothelial homeostasis. As Ang-1 has been shown to have anti-apoptotic effects on endothelial cells, ${ }^{17}{ }^{18}$ we speculate that because of the endothelial damage in SCD, Ang-1 levels are raised in order to provide this support. Our observation of a significant correlation between Ang-1 and vWf in SCD, but not in controls, lends support to this hypothesis.

Destabilisation of growing blood vessels by Ang-2, in the absence of VEGF, leads to vessel regression, whereas such destabilisation in the presence of high VEGF levels facilitates the angiogenic response. ${ }^{9-11}$ Thus, the precise balance of VEGF and the angiopoetin/Tie-2 system is important in determining whether or not vessels auto-infarct and regress/ atrophy or proliferate and become leaky. We would therefore expect that in PSR patients, retinal vaso-occlusion leads to retinal ischaemia and hypoxia, which induces high levels of VEGF and Ang-2. Conversely, in patients without retinopathy, there might be relatively greater retinal vaso-occlusion possibly also accompanied by greater levels of auto-infarction-leading to less retinal ischaemia and less hypoxia than in PSR patients, and lower levels of VEGF and Ang-2 than in PSR patients. It follows that Ang-2, in the presence of very low levels of VEGF, might induce neovascular regression.

An "angiogenic index," reflecting the ratio of Ang-2 to VEGF and/or the combined angiopoietins to VEGF might be indicators of the presence or development of PSR, with a low index (high Ang-2/high VEGF) indicating the tendency to new vessel proliferation and leakiness, and a high index (mid-high Ang2/low VEGF) indicating tendency to neovascular regression and atrophy. Our observations of lower ratios of the angiopoietins (individually or combined) in SCD compared to AA subjects as well as the trend of lower Ang-2/ VEGF from "no retinopathy" to PSR is consistent with this. In SCD, the strong intercorrelations among the growth factors, suggest a high degree of coordinated and complementary angiogenic activity and perhaps a role for these factors in abnormal angiogenesis in SCD; however, no clear patterns emerged according to severity of retinopathy.

The role of the angiopoietins and their interaction with VEGF (if any) in retinal neovascularisation is not fully understood. In human retinal tissue, Ang-2 and Tie-2 expression appears to be associated with ischaemic retinal disorders ${ }^{19}$ and VEGF expression with abnormal proliferation in SCD. ${ }^{20}$ However, the idea that angiogenic activity is further heightened in SCD patients with PSR was not supported by the present findings. The observed lack of difference in any molecule among the SCD patients may be attributable to their existing elevated levels that may obscure any further increase in their levels in different eye conditions.

\section{ACKNOWLEDGEMENTS}

We thank the staff of the Sickle Cell and Thalassemia Centre, City Hospital, for their support of this research. We gratefully acknowledge the funding of the Sandwell and West Birmingham Hospitals NHS Trust Research and Development programme for the Haemostasis Thrombosis and Vascular Biology Unit.

\section{Authors' affiliations}

J S Mohan, A D Blann, G Y H Lip, Haemostasis, Thrombosis and Vascular Biology Unit, University Department of Medicine, The Birmingham and Midland Eye Centre, City Hospital, Birmingham B18 7QH, UK

J S Mohan, D Bareford, Department of Haematology, The Birmingham and Midland Eye Centre, City Hospital, Birmingham B18 7QH, UK P L Lip, Department of Ophthalmology, The Birmingham and Midland Eye Centre, City Hospital, Birmingham B18 7QH, UK

Correspondence to: Professor G Y H Lip, University Department of Medicine, City Hospital, Birmingham B18 7QH, UK; g.y.h.lip@bham. ac.uk

Accepted 12 November 2004

\section{REFERENCES}

1 Moriarty BJ, Acheson RW, Condon PI, et al. Patterns of visual loss in untreated sickle cell retinopathy. Eye 1988;2:330-5.

2 Goldberg MF. Natural history of untreated proliferative sickle retinopathy Arch Ophthalmol 1971;85:428-37.

3 Fox PD, Rupert Vessey SJ, Forshaw ML, et al. Influence of genotype on the natural history of untreated proliferative sickle retinopathy-an angioraphic study. Br J Ophthalmol 1991;75:229-31.

4 Shima DT, Deutsch U, D'Amore PA. Hypoxic induction of vascular endothelial growth factor (VEGF) in human epithelial cells is mediated by increases in mRNA stability. FEBS Lett 1995;370:203-8.

5 Aiello LP, Avery RL, Arrigg PG, et al. Vascular endothelial growth factor in ocular fluid of patients with diabetic retinopathy and other retinal disorders. N Engl J Med 1994;331:1480-7.

6 Aiello LP, Northrup JM, Keyt BA, et al. Hypoxic regulation of vascular endothelial growth factor in retinal cells. Arch Ophthalmol 1995; 113:1538-44

7 Lip PL, Belgore F, Blann AD, et al. Plasma VEGF and soluble VEGF receptor Flt-1 in proliferative retinopathy; relationship to endothelial dysfunction and laser treatment. Invest Ophthalmol Vis Sci 2000;41:21 15-19.

8 Barleon B, Hauser S, Schollmann C, et al. Differential expression of the two VEGF receptors flt and KDR in placenta and vascular endothelial cells. J Cell Biochem 1994;54:56-66.

9 Maisonpierre PC, Suri C, Jones PF, et al. Angiopoietin-2, a natural antagonist for Tie-2 that disrupts in vivo angiogenesis. Science 1997;277:55-60.

10 Holash J, Maisonpierre PC, Compton D, et al. Vessel cooption, regression, and growth in tumors mediated by angiopoietins and VEGF. Science 1999;284: 1994-8. 
11 Holash J, Wiegand SJ, Yancopoulos GD. New model of tumor angiogenesis: dynamic balance between vessel regression and growth mediated by angiopoietins and VEGF. Oncogene 1999;18:5356-62

12 Mandriota SJ, Pepper MS. Regulation of angiopoietin-2 mRNA levels in bovine microvascular endothelial cells by cytokines and hypoxia. Circ Res 1998;83:852-9.

13 Oh H, Takagi H, Suzuma K, et al. Hypoxia and vascular endothelial growth factor selectively up-regulateangiopoietin-2 in bovine microvascular endothelial cells. J Biol Chem 1999:274:15732-9.

14 Otani $\mathrm{A}$, Takagi $\mathrm{H}, \mathrm{Oh} \mathrm{H}$, et al. Expressions of angiopoietins and Tie- 2 in human choroidal neovascular membranes. Invest Ophthalmol Vis Sci 1999;40:1912-20.

15 Solovey A, Gui L, Ramakrishnan S, et al. Sickle cell anemia as a possible state of enhanced anti-apoptotic tone: survival effect of vascular endothelial growth factor on circulating and unanchored endothelial cells. Blood 1999;93:3824-30.
16 Blann AD, Marwah S, Serieant G, et al. Platelet activation and endothelial cell dysfunction in sickle cell disease is unrelated to reduced antioxidant capacity. Blood Coag Fibrinolys 2003; 14:255-9.

17 Kim I, Kim HG, So JN, et al. Angiopoietin-1 regulates endothelial cell survival through the phosphatidylinositol $3^{\prime}$-Kinase/Akt signal transduction pathway. Circ Res 2000;86:24-9.

18 Harfouche R, Hassessian HM, Guo Y, et al. Mechanisms which mediate the antiapoptotic effects of angiopoietin-1 on endothelial cells. Microvasc Res 2002:64:135-47

19 Takagi H, Koyama S, Seike H, et al. Potential role of the angiopoietin/Tie-2 system in ischemia-induced retinal neovascularization. Invest Ophthalmol Vis Sci 2003;44:393-402

20 Cao J, Mathews MK, McLeod DS, et al. Angiogenic factors in human proliferative sickle cell retinopathy. Br J Ophthalmol 1999;83:838-46.

\section{Clinical Evidence - Call for contributors}

Clinical Evidence is a regularly updated evidence-based journal available worldwide both as a paper version and on the internet. Clinical Evidence needs to recruit a number of new contributors. Contributors are healthcare professionals or epidemiologists with experience in evidence-based medicine and the ability to write in a concise and structured way.

Areas for which we are currently seeking authors:

- Child health: nocturnal enuresis

- Eye disorders: bacterial conjunctivitis

- Male health: prostate cancer (metastatic)

- Women's health: pre-menstrual syndrome; pyelonephritis in non-pregnant women However, we are always looking for others, so do not let this list discourage you.

Being a contributor involves:

- Selecting from a validated, screened search (performed by in-house Information Specialists) epidemiologically sound studies for inclusion.

- Documenting your decisions about which studies to include on an inclusion and exclusion form, which we keep on file.

- Writing the text to a highly structured template (about 1500-3000 words), using evidence from the final studies chosen, within 8-10 weeks of receiving the literature search.

- Working with Clinical Evidence editors to ensure that the final text meets epidemiological and style standards.

- Updating the text every six months using any new, sound evidence that becomes available. The Clinical Evidence in-house team will conduct the searches for contributors; your task is simply to filter out high quality studies and incorporate them in the existing text.

- To expand the topic to include a new question about once every 12-18 months.

If you would like to become a contributor for Clinical Evidence or require more information about what this involves please send your contact details and a copy of your CV, clearly stating the clinical area you are interested in, to Klara Brunnhuber (kbrunnhuber@ bmigroup.com).

\section{Call for peer reviewers}

Clinical Evidence also needs to recruit a number of new peer reviewers specifically with an interest in the clinical areas stated above, and also others related to general practice. Peer reviewers are healthcare professionals or epidemiologists with experience in evidence-based medicine. As a peer reviewer you would be asked for your views on the clinical relevance, validity, and accessibility of specific topics within the journal, and their usefulness to the intended audience (international generalists and healthcare professionals, possibly with limited statistical knowledge). Topics are usually 1500-3000 words in length and we would ask you to review between 2-5 topics per year. The peer review process takes place throughout the year, and our turnaround time for each review is ideally 10-14 days.

If you are interested in becoming a peer reviewer for Clinical Evidence, please complete the peer review questionnaire at www.clinicalevidence.com or contact Klara Brunnhuber (kbrunnhuber@bmigroup.com). 